\title{
Advance-Platelet Rich Fibrin and Hyaluronic Acid Combination Improves Interleukin-6 and Granulation Index in Diabetic Foot Ulcer Patients
}

\author{
Ronald Winardi Kartika ${ }^{1,2}$, Idrus Alwi ${ }^{3}$, Franciscus Dhyanagiri Suyatna ${ }^{4}$, Em Yunir ${ }^{3}$, \\ Sarwono Waspadji ${ }^{3}$, Suzzana Immanuel ${ }^{5}$, Todung Silalahi ${ }^{6}$, Saleha Sungkar ${ }^{7}$, Jusuf Rachmat $^{8}$, \\ Saptawati Bardosono ${ }^{9}$, Mirta Hediyati Reksodiputro ${ }^{10, *}$

\begin{abstract}
${ }^{1}$ Doctoral Program in Medical Science, Faculty of Medicine, Universitas Indonesia, Jl. Salemba Raya No.6, Jakarta, Indonesia ${ }^{2}$ Department of Thoracic, Cardiac and Vascular Surgery, Krida Wacana Christian University, Jl. Arjuna Utara No.6, Jakarta, Indonesia Jakarta, Indonesia

${ }^{4}$ Department of Clinical Pharmacology, Faculty of Medicine, Universitas Indonesia, Jl. Salemba Raya No.6, Jakarta, Indonesia Jakarta, Indonesia

${ }^{6}$ Department of Internal Medicine, Krida Wacana Christian University, Jl. Arjuna Utara No.6, Jakarta, Indonesia

${ }^{7}$ Department of Clinical Parasitology, Faculty of Medicine, Universitas Indonesia, Jl. Salemba Raya No.6, Jakarta, Indonesia ${ }^{9}$ Department of Nutrition, Faculty of Medicine Universitas Indonesia, Jl. Salemba Raya No.6, Jakarta, Indonesia General Hospital, Jl. Salemba Raya No.6, Jakarta, Indonesia
\end{abstract} \\ ${ }^{3}$ Department of Internal Medicine, Faculty of Medicine, Universitas Indonesia/Cipto Mangunkusumo General Hospital, J1. Salemba Raya No.6, \\ ${ }^{5}$ Department of Clinical Pathology, Faculty of Medicine, Universitas Indonesia/Cipto Mangunkusumo General Hospital, Jl. Salemba Raya No.6, \\ ${ }^{8}$ Department of Thoracic Cardiac and Vascular Surgery, Faculty of Medicine ,Universitas Indonesia, Jl. Salemba Raya No.6, Jakarta, Indonesia \\ ${ }^{10}$ Facial Plastic Reconstructive Division, Department of Otorhinolaryngology, Faculty of Medicine, Universitas Indonesia/Cipto Mangunkusumo \\ *Corresponding author. E-mail: citamirta@yahoo.com
}

Received date: Jan 24, 2021; Revised date: Mar 18, 2021; Accepted date: Mar 24, 2021

\section{Abstract}

$\mathrm{B}$ ACKGROUND: Diabetic foot ulcer (DFU) is the most common and threatening complication of Diabetes Mellitus (DM). Ideal wound dressing for DFU management should relieve symptoms, provide wound protection, and encourage healing. AdvancedPlatelet Rich Fibrin (A-PRF) and Hyaluronic Acid (HA) have been proven to improve wound healing process. This study was aimed to demonstrate the ability of combination of A-PRF and HA in reducing inflammation and improving DFU tissue healing.

METHODS: Twenty DFU subjects were involved in this study, and divided into two groups based on the topical fibrin gel treatment: A-PRF + HA group and A-PRF only group. A-PRF was obtained by peripheral blood centrifugation. A-PRF + HA was prepared by homogening A-PRF and AH with a ratio of 1:0.6. Interleukin-6 (IL-6) level, granulation index (GI), numeric pain score (NPS), and inflammation clinical symptoms (ICS) were assessed on day- $0,3,7$ and 14 .

RESULTS: Wound swabs' IL-6 level on day-7 was found to be significantly lower in A-PRF + HA compared to A-PRF alone $(p=0.041)$. The IL-6 level reduction also found to be significant higher either in wound swabs (day $0-7, p=0.015$ ) or fibrin gel (day $0-3, p=0.049$; day $0-7, p=0.034$ ). A-PRF + HA treatment significantly increased the GI even since day-3 ( $p=0.043)$, with lower NPS $(p<0.001)$, and ICS score.

CONCLUSION: The combination of A-PRF and HA increases the GI in DFU healing by reducing the inflammation state which will induce the angiogenesis process, as well as reducing pain in DFU subjects better than A-PRF alone.

KEYWORDS: inflammation, interleukin-6, wound healing, angiogenesis, proliferation

Indones Biomed J. 2021; 13(2): 170-7 


\section{Introduction}

Diabetic foot ulcer (DFU) is the most common and devastating complications of diabetes mellitus (DM), associated with neuropathy and/or peripheral arterial disease of the lower limb in DM patients. This serious condition not only affect the patient's health by increasing the mortality risk up to 2.5 folds (1), and requires intensive care, but also have a socioeconomic impact (2). Diabetic population has a prevalence of $19-34 \%$ for diabetic foot ulceration, means that 9.1-26.1 millions of DM patients will develop DFU each year.(3)

Wound dressings is one of the important management of DFU. The dressings ideally should relieve symptoms, provide wound protection, and encourage healing.(4) The use of a moist bandage is an option to prevent tissue dehydration and cell death, accelerated angiogenesis, and allows interaction between growth factors and target cells. Recently, a wide variety of dressings are available from standard treatment to adjuvant therapy. In addition, DFU management requires wound loading, vascular assessment, treatment of infection and glycemic control.(5)

In addition to DFU standard management, a wide variety of agents are available and developed as adjuvant therapies, including oxygen therapy, negative pressure wound therapy, acellular bioproducts, growth factors, biologically engineered skin and skin grafts, energy-based therapy, and systemic therapy. $(6,7)$ Hyaluronic acid (HA), the main component of the extracellular matrix, also known to play key roles in tissue regeneration and wound healing process by modulating inflammation, cell migration, and angiogenesis via specific HA receptors. Most of these adjuvant therapy utilize the benefit of fibroblast growth factors, epidermal growth factors, endothelial vascular growth factors, granulocyte colony stimulating factors, and platelet-derived growth factors.(8) Some studies showed the benefit of platelet-derived growth factor in wound healing. However, there is limited data on on the benefits of growth factor for DFU.

Autologous platelet-rich plasma (PRP) have been widely used for wound healing. PRP collected by centrifuging patient's own blood sample to separate the highly concentrated suspensions rich in platelet growth factors. The growth factor then released from the platelet granules of PRP by adding $\mathrm{CaCl}_{2}$.(9) Some current developing technologies not using platelet suspensions anymore, but a solid fibrin-based biomaterials called PlateletRich Fibrin (PRF) instead.(10) Advanced-Platelet Rich
Fibrin (A-PRF) was then further developed from Standard Choukrone platelet-rich fibrin (S-PRF) by modifying the centrifugation speed and time into $1500 \mathrm{rpm}$ for 14 minutes. Slower rotation and shorter time of centrifugation affect the amount of growth factors and cytokines release by macrophage.(11) Some studies showed that combining HA with PRP exhibits anti-inflammatory properties in subjects with knee osteoarthritis.(12)

In patients with DFU, the process of wound healing is delayed due to prolonged inflammation, and inhibit growth factors to form granulation tissue in the proliferation and epithelialization phases needed for wound healing.(13) Both HA and A-PRF have an anti-inflammatory property. Combining HA with A-PRF is expected to optimize their anti-inflammatory activity by decreasing interleukin-6 (IL6), increasing the angiogenesis and take benefit from HA's antioxidant property (14), thus improve the granulation which can be assessed macroscopically using imageJ (15). Until now there have been no studies comparing the combination of A-PRF and HA with A-PRF alone in reducing inflammation which affects the healing of DFU. This study was aimed to demonstrate the ability of combination of A-PRF and HA in reducing inflammation and improving DFU tissue regeneration through the role of the major cellular receptors involved in HA signalling.

\section{Methods}

This study had been approved by The Institutional Board of the Faculty of Medicine Universitas, Indonesia (No. 0855/UN2.F1/ETIK/2018). This open-label randomized controlled trial was conducted at Koja District Hospital and Gatot Soebroto Hospital from July 2019 to April 2020.

\section{Study Subjects}

DFU subjects age $>18$ years old, with chronic ( $>4$ weeks) wounds on lower limbs, Wagner-2, and ulcer size $<40$ $\mathrm{cm}^{2}$ were recruited and randomly assigned for A-PRF + HA group, A-PRF group and control group. Subjects with International Working Group on the Diabetic Foot (IWGDF) score infection $<2$, platelet level $<8.0 \mathrm{~g} / \mathrm{L}$, Hemoglobin A1C (HbAlc) $>12.0 \%(108 \mathrm{mmol} / \mathrm{mol})$, impaired kidney function, with haemophilia, sickle cell anaemia, leukemia, peripheral arterial disease, or with incomplete data were excluded. On day-0, day-3 and day-7, samples from wound swabs and fibrin gel, and photographs were taken. The examination was performed at the Integrated Laboratory, Faculty of Medicine, Universitas Indonesia. 


\section{A-PRF Gel Preparation}

Twenty to forty $\mathrm{mL}$ of autologous peripheral blood was taken without anticoagulant, then centrifuged $200 \mathrm{~g}$ for 8 minutes. Fibrin and buffy coat were then separated from the erythrocytes, and A-PRF gel was obtained. For A-PRF + HA gel preparation, the process was continued by making A-PRF and HA homogenate with a ratio of $1 \mathrm{~mL}: 0.6 \mathrm{~mL}$ with vortex for 20 seconds. About $0.5 \mathrm{~mL}$ of each fibrin gel was separated and stored in the refrigerator at $-80^{\circ} \mathrm{C}$ for IL-6 measurement on day-3 and 7.

\section{Application of A-PRF or A-PRF + HA in DFU}

The wound was first cleaned and debrided. Assessment for IL-6 and granulation index (GI) were made before any fibrin gel application, recorded as day-0. After the assessment, $1 \mathrm{~mL}$ of fibrin gel (A-PRF + AH, or A-PRF alone) was applied topically on the wound area of $10 \mathrm{~cm}^{2}$. A sterile gauze was then applied to cover the wound as a secondary dressing to maintain moisture. The treatments were applied for 3 times on day-0, 3 and 7. After day-7, only a standard $\mathrm{NaCl}$ therapy was given to the subjects until day-14.

\section{Measurement of IL-6 Level}

IL-6 level was measured in $\mathrm{pg} / \mathrm{mL}$ from wound swabs and the fibrin gel on day-0, 3, 7, and 14 using enzyme-linked immunosorbent assay (ELISA) (Cat \#LS-F4604, LifesSpan BioSciences, Seattle, WA, United States). Swabbing was performed by the same person during the experiment to ensure equal swabbing pressure. The swab was swept once in the wound's center, and the gauze swab was transferred to a tube containing $2 \mathrm{~mL} \mathrm{NaCl}$, mixed well for 5 minutes and the lysate was separated. The lysate was kept in $-80^{\circ} \mathrm{C}$. Fibrin gel sample was obtained by cutting about $0.5 \mathrm{~mL}$ freezed gel preparate. Both swabs and fibrin gel samples were thawed in room temperature. Samples were then centrifuged for 20 minutes at $1000 \times \mathrm{g}$ to remove particulates. The supernatant was collected. One hundred $\mu \mathrm{L}$ of Standard, Sample, or Blank were added to each well and incubate for 90 minutes at room temperature, then was aspirated and washed 3 times. One hundred $\mu \mathrm{L}$ of Biotinylated Detection Antibody was added and incubated for 1 hour at $37^{\circ} \mathrm{C}$, then was aspirated and washed 3 times. One hundred $\mu$ of HRPStreptavidin Conjugate was added and incubated for 45 minutes at $37^{\circ} \mathrm{C}$, then was aspirated and washed for 5 times. One hundred $\mu \mathrm{L}$ of TMB Substrate solution and incubated for $\sim 15-30$ minutes at $37^{\circ} \mathrm{C}$ in the dark. One hundred $\mu \mathrm{L}$ of Stop Solution was added, then was read immediately at $450 \mathrm{~nm}$.

\section{Assessment for Wounds Improvement}

The wound's area improvement was recorded using a digital camera 48 mega pixel with an accuracy of $0.1 \%$ on day- 0 , 3,7 , and 14. The results of the wound photographs were processed using Image-J (National Institutes of Health, Bethesda, MD, USA) and the GI was evaluated. GI was counted as the ratio between granulation area to wound area, in percent. Pain response was recorded using numeric pain score (NPS), and inflammation state was assessed cliniccaly by inflammation clinical symptoms (ICS).(16)

\section{Statistical Analysis}

IBM SPSS software v.20 (IBM Coorporation, Armonk, NY, USA) was used for all statistical analysis. Statistical significance was determined at the 5\% level. The general data description was presented in mean $\pm \mathrm{SD}$, and the median (range) value. The parameter's differences were conducted using Mann-Whitney u test and independent t-test.

\section{Results}

Twenty subjects with DFU were involved in this study. The subjects were randomly divided into two groups according to fibrin gel applied (A-PRF + HA, and A-PRF alone). A-PRF + HA group had five women and five men, while the A-PRF group had six women and four men. The subjects' characteristic were already presented in our previous publication.(17) There were no significance differences between the two groups' characteristics.

\section{IL-6 Level in Wound Swabs and the Fibrin Gel}

In order to observe the inflammation's role in DFU healing process, IL-6 levels were measured. There were no differences of IL-6 level in both groups at day-0 (before any treatments), either in wound swabs or the fibrin gel as shown in Table 1. The significant differences of IL-6 level between $\mathrm{A}-\mathrm{PRF}+\mathrm{HA}$ and A-PRF alone were found in wound swabs sample on day-7 ( $p=0.041)$, while in fibrin gel, the A-PRF + HA samples have shown a higher level of IL- 6 even on day$3(p=0.038)$. The reduction of IL-6 level also found to be significant higher in A-PRF + HA samples either in wound swabs (day $0-7, p=0.015$ ) or fibrin gel (day $0-3, p=0.049$; day $0-7, p=0.034)$.

\section{DFU's GI}

GI was assessed to observe the role of angiogenesis in DFU improvement. The average GI can be found in Table 2 and Figure 1. A-PRF + HA treatment was significantly improved 
Table 1. IL-6 level (pg/mL) differences between treatments.

\begin{tabular}{|c|c|c|c|c|c|c|}
\hline \multirow[b]{2}{*}{ Treatment } & \multicolumn{3}{|c|}{ Fibrin Gel } & \multicolumn{3}{|c|}{ Wound Swabs } \\
\hline & $\begin{array}{c}\text { A-PRF + HA } \\
(n=10)\end{array}$ & $\begin{array}{l}\text { A-PRF } \\
(n=10)\end{array}$ & $p$-value ${ }^{a}$ & $\begin{array}{c}A-P R F+H A \\
(n=10)\end{array}$ & $\begin{array}{c}\text { A-PRF } \\
(n=10)\end{array}$ & $p$-value ${ }^{\text {b }}$ \\
\hline Day-0 & $0.07 \pm 0.03$ & $0.09 \pm 0.14$ & 0.059 & $106.4(83.1-407.6)$ & $91.9(38.6-151.6)$ & 0.337 \\
\hline Day-3 & $0.05 \pm 0.02$ & $0.07 \pm 0.03$ & $0.038^{*}$ & $99.5(76.3-302.2)$ & $72.8(27.1-148.9)$ & 0.119 \\
\hline Day-7 & $0.03 \pm 0.03$ & $0.04 \pm 0.04$ & $0.034^{*}$ & $88.7(44.3-217.9)$ & $48.8(27.7-116.2)$ & $0.041^{*}$ \\
\hline$\Delta$ Day $0-3$ & $26.0 \pm 8.4$ & $12.5 \pm 6.2$ & $0.049 *$ & $-10.9(-26.8-10.4)$ & $-3.7(-11.5-3.5)$ & 0.46 \\
\hline$\Delta$ Day $0-7$ & $41.7 \pm 13.8$ & $29.0 \pm 9.2$ & $0.034 *$ & $-18.3(-64.9-44.6)$ & $-7.8(-24.6-5.4)$ & $0.015^{*}$ \\
\hline
\end{tabular}

${ }^{\mathrm{a}}$ mean $\pm \mathrm{SD}$, independent t-test; ${ }^{\mathrm{b}}$ Median (min-max), Mann Whitney test; * significant at $p<0.05$.

the wound compares to A-PRF alone even since day-3 $(p=0.043)$. There were significant GI increasing from day- 0 to day-3 $(p=0.006)$, day-7 $(p=0.004)$ and day-14 $(p=0.049)$ in A-PRF + HA group compare to A-PRF alone.

Figure 1 shows the GI observed at day-0, 3, 7, and 14 on different treatment groups. Here, we observed different rate of wound closure and healing, especially at day-14 compared to day- 0 (before any treatment).

\section{NPS and ICS Evaluation in DFU Subjects}

NPS and ICS were assessed to observe the subject's clinical condition related to the DFU. In NPS evaluation, day- 0 examination of both groups scored between 7-8 (severe pain). After treatments, the pain scores decreased in both groups. Furthermore, A-PRF + HA group showed a significantly lower NPS on day-3 $(p<0.001)$ compare to A-PRF alone, as showed in Table 3 and Figure 2.

Figure 2 shows that the NPS in A-PRF + HA group was significantly lower compares to A-PRF group on day-3 $(p<0.001)$, and day-7 ( $p=0.029)$, but not significant different on day-14 ( $p=0.957)$.
Patients' inflammatory state was assessed by ICS including redness, heat, swelling, pain, and functio laesa before and after treatments. A-PRF + HA group showed a significantly lower ICS score after day-7 compare to A-PRF group as showed in Table 4.

\section{Discussion}

Type 2 DM patients with blood glucose level higher than $300 \mathrm{mg} / \mathrm{dL}$ usually have problems in wound healing, due to the growth factors impairment.(18) DFU treatment with growth factors supplementary such as transforming growth factor (TGF)- $\beta 1$ and $\beta 2$, insulin-like growth factor (IGF), and vascular endothelial growth factor (VEGF) has begun to be developed in the late decades, to improve new cell growth and wound healing.(19-21) These growth factors also used in orthopaedics, maxillofacial, periodontal fields, plastic surgery, and sports medicine because of their antiinflammatory and antimicrobial properties.(22) The DFU healing after growth factor application characterized by

Table 2. GI (\%) difference between treatments.

\begin{tabular}{lccc}
\hline \multirow{2}{*}{ Treatment } & \multicolumn{2}{c}{ Mean \pm SD } & \\
\cline { 2 - 3 } & $\begin{array}{c}\text { A-PRF + HA } \\
(\mathbf{n}=\mathbf{1 0})\end{array}$ & $\begin{array}{c}\text { A-PRF } \\
(\mathbf{n}=\mathbf{1 0})\end{array}$ & -value* \\
\hline Day-0 & $38.2 \pm 14.4$ & $36.0 \pm 15.7$ & 0.910 \\
Day-3 & $64.2 \pm 14.6$ & $48.5 \pm 19.0$ & $0.043^{*}$ \\
Day-7 & $79.9 \pm 1.6$ & $65.0 \pm 18.2$ & $0.049^{*}$ \\
Day-14 & $95.9 \pm 0.4$ & $86.9 \pm 15.3$ & $0.041^{*}$ \\
\hline$\Delta$ Day 0-3 & $26.0 \pm 8.4$ & $12.5 \pm 6.2$ & $0.006^{*}$ \\
$\Delta$ Day 0-7 & $41.7 \pm 13.8$ & $29.0 \pm 9.2$ & $0.004^{*}$ \\
$\Delta$ Day 0-14 & $57.7 \pm 14.1$ & $50.9 \pm 17.6$ & $0.049^{*}$ \\
\hline
\end{tabular}

${ }^{a}$ mean $\pm \mathrm{SD}$, independent t-test; * significant at $p<0.05 ; \Delta=\mathrm{GI}$ difference from day-0 to day-N. 


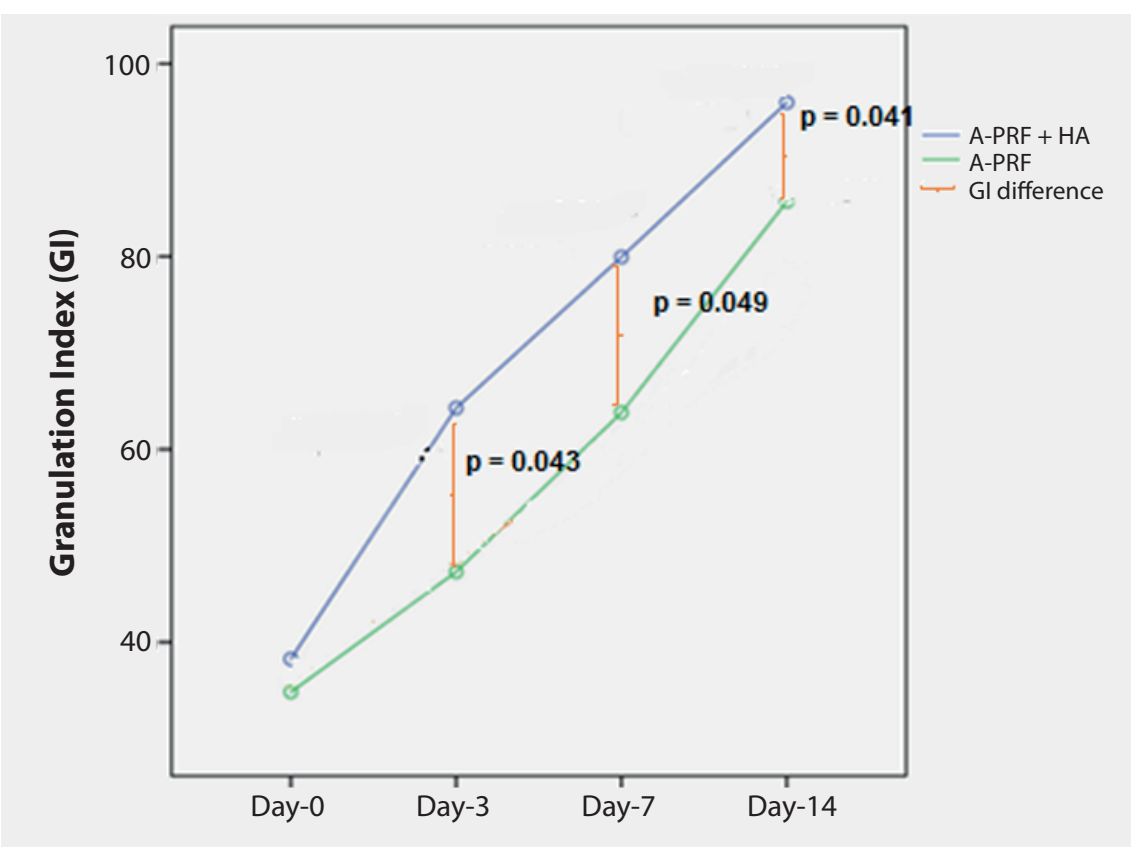

Figure 1. GI of DFU on day-0, 3, 7, and 14.

granulation tissue formation. An increased level of IL-6 was reported in plasma in diabetic subjects with foot ulceration compared with diabetics without foot complications.(22)

In this study, $20 \mathrm{DFU}$ subjects with similar basic characteristics were involved. A-PRF + HA group showed a significant reduction in inflammation both in wound swabs ( $p=0.015$ ), and fibrin gel preparation $(p=0.034)$. the subjects' clinical observation also showed a significant improvement for GI, NPS and ICS.

Delays in diabetic wound healing associated with increased IL-6, IL-6R $\alpha$ expression, and signal transducer and activator of transcription 3 (STAT3) activation, yet lower suppressor of cytokine signaling 3 (SOCS3) expression in the skin.(23) IL-6 and its receptor may play important roles in diabetic wound healing. IL-6 is produced in DFU with chronic inflammation. The nature of IL-6 is to change the leukocyte infiltrates, from polymorphonuclear neutrophils to monocytes / macrophages. In addition, IL-6 stimulates $\mathrm{T}$ and $\mathrm{B}$ cells, which support a chronic inflammatory response.(24)

The inflammatory status of DFU can be observed both locally and systemically. In this study, a DFU swab was performed locally using a cotton swab and the inflammatory mediators IL-6 was measured. This examination is novel and has never been done before. Usually DFU assessment for biomarkers was performed through a more invasive techniques such as tissue biopsy or patch skin biopsy. Systemic inflammation can be measured from patients' serum. In this study, we measured the IL-6 from A-PRF + HA or A-PRF fibrin gel. PRF lysates incubated in a conditioned medium elicits an anti-inflammatory effect showed by IL-1 $\beta$ measurements.(25) PRF lysate polarizes M2 macrophages phenotype and express arginase-1 (ARG1) and YM1 gene which supports angiogenesis. $(26,27)$

Table 3. NPS median differences in DFU subjects.

\begin{tabular}{lccc}
\hline \multirow{2}{*}{ Treatment } & \multicolumn{2}{c}{ Median (Min-Max) } & \\
\cline { 2 - 3 } & $\begin{array}{c}\text { A-PRF + HA } \\
(\mathbf{n}=\mathbf{1 0})\end{array}$ & $\begin{array}{c}\text { A-PRF } \\
(\mathbf{n}=\mathbf{1 0})\end{array}$ & $\boldsymbol{p}$-value* \\
\hline Day-0 & $8(8-9)$ & $8(7-8)$ & 0.164 \\
Day-3 & $4(3-5)$ & $5(5-6)$ & $0.000^{*}$ \\
Day-7 & $2.5(1-3)$ & $3(3-5)$ & $0.029^{*}$ \\
Day-14 & $2.1(2-4)$ & $2(2-3)$ & 0.957 \\
\hline
\end{tabular}

$0=$ no pain; $1-3=$ mild $; 4-6=$ moderate; $7-9=$ severe.

*significant at $p<0.05$, Mann-Whitney test; 


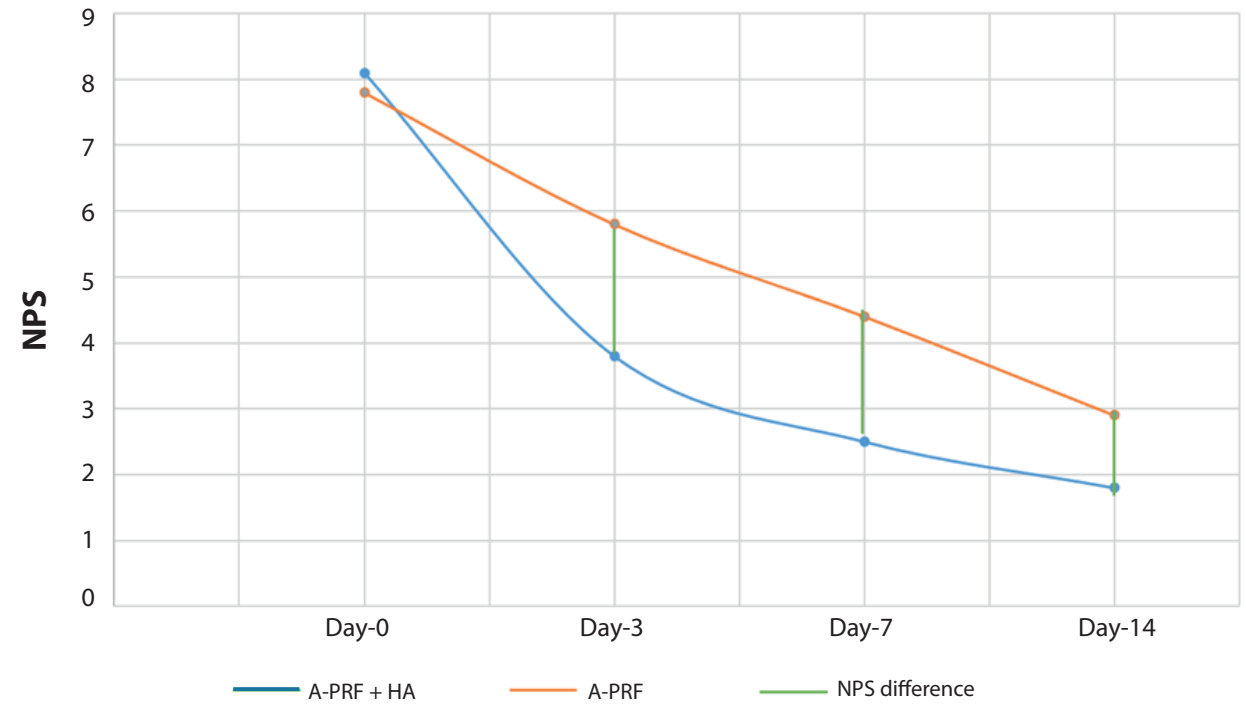

Figure 2. NPS in DFU subjects before and after treatments.
Many natural growth factors were developed from autologous platelet concentrate including PRP and PRF. PRP releases growth factor from the granules when it was activated, increases the fibroblasts proliferation rate in wound healing.(28) A-PRF, a second generation of PRP also plays a role in the proliferation phase by continuously releasing growth factors such as TGF- $\beta 1$ and PDGF-AA at the wound site and inducing cells' viability, proliferation and differentiation. A-PRF was first described in 2014 as a new concept for cell-based tissue engineering by lowering the rpm when centrigued, and reducing the time. Venous blood is drawn without adding anticoagulants to obtain A-PRF. The S-PRF protocol is to use a speed of $2700 \mathrm{rpm}$ or $360 \times \mathrm{g}$ centrifuge for 12 minutes. In contrast to S-PRF, the A-PRF was obtained by a low-speed centrifuge $(1500 \mathrm{rpm}$ or $200 \times \mathrm{g}$ for 8 minutes) because centrifugal force (speed and time) affects the distribution of suitable growth factor's cells for wound healing and tissue regeneration.(27)

Table 4. ICS score in DFU subjects.

\begin{tabular}{lccc}
\hline & \multicolumn{2}{c}{ Mean \pm SD } & \\
\cline { 2 - 3 } Sign of Inflammation & $\begin{array}{c}\text { A-PRF }+ \text { HA } \\
(\mathbf{n}=\mathbf{1 0})\end{array}$ & $\begin{array}{c}\text { A-PRF } \\
(\mathbf{n}=\mathbf{1 0})\end{array}$ & -value \\
\hline Redness & $2.9 \pm 0.5$ & & \\
Day-0 & $0.1 \pm 0.03$ & $2.5 \pm 1.1$ & 0.89 \\
Day-7 & & $1.1 \pm 0.3$ & $0.008^{*}$ \\
\hline Heat & $2.8 \pm 0.1$ & & 0.707 \\
Day-0 & $0.3 \pm 0.1$ & $2.4 \pm 0.5$ & $0.022^{*}$ \\
Day-7 & & $0.8 \pm 0.2$ & 0.179 \\
\hline Swelling & $2.9 \pm 0.2$ & & $0.001^{*}$ \\
Day-0 & $0.1 \pm 0.05$ & $2.5 \pm 0.3$ & \\
Day-7 & & $0.8 \pm 0.1$ & 0.328 \\
\hline Pain & $2.9 \pm 0.5$ & & $0.002^{*}$ \\
Day-0 & $0.2 \pm 0.4$ & $2.7 \pm 0.6$ & $0.9 \pm 0.2$ \\
Day-7 & & & $0.053^{*}$ \\
\hline Functio Laesa & $2.5 \pm 0.3$ & $2.6 \pm 0.2$ & \\
Day-0 & $0.3 \pm 0.1$ & $0.4 \pm 0.1$ & \\
Day-7 & & & \\
\hline
\end{tabular}

$0=$ none; $1=$ mild $; 2=$ moderate $3=$ severe.

*significant at $p<0.05$, t-test. 
HA recruits macrophages and modulates the inflammatory response.(25) HA also has antioxidant and anti-inflammatory properties so it is widely used to treat osteoarthritis (OA). HA is able to build connective tissue and functions to stabilize the intercellular structure and form a matrix of collagen and elastic fibers.(29) HA inhibits the collagenase, which is the proteolysis enzyme of collagen.(27) HA also affects cell migration, cell adhesion and angiogenesis. Fibroblasts play a major role in wound healing by forming extracellular matrix components such as collagen, elastin and proteoglycans. Fibroblasts also play an important role in the migration of keratinocytes from the wound edges to achieve wound closure and matrix reconstruction resulting in maximal wound healing force of contraction.(29)

At the beginning of wound healing, during the inflammatory phase, the role of IL-6 is very important. But as it moves into the proliferation and regeneration phase, the inflammatory process will decrease. If the inflammatory process is prolonged such as in DFU, the healing process of the wounds and the formation of granulation tissue will be inhibited. An anti-inflammatory agent is needed in this case to improve the wound healing process.(25)

In this study, the combination of A-PRF and HA significantly increases GI, while decreases IL-6 in day3 dan day-7. A-PRF and HA combination, via the Erk1/2 pathway and the Smad 2/3 pathway, will reduce the number of pro-inflammatory cytokines, increase the proliferation of articular chondrocytes, and chondrogenic differentiation. The clinical application of A-PRF and HA combination is more effective than PRF or HA alone; though both are therapeutic options for osteoarthritis and chronic tendinopathy.

The combination of HA with PRF stimulated growth factors such as TGF- $\beta$, significantly increasing the proliferation index and collagen deposition.(30) HA also interacts with the TGF- $\beta 1$ transformation of PRF, thereby protecting growth factors from the degradation of tryptic and collagen by protease enzymes. Another study aobserved that the combination of HA with L-PRF reduced edema after the 3rd molar oral surgery through HA linking wih (Intercellular Adhesion Molecule (ICAM) and vascular cell adhesion molecule (VCAM) receptor. This link will reduce vascular leakage of neutrophil and reduce edema.(31)

HA affects three main receptors in the modulation of tissue regeneration, namely migration, proliferation and activation of keratinocyte cells, such as CD44. This is done to restore the epidermis, fibroblast migration, control of inflammation and neoangiogenesis, as well as promotion of extracellular matrix (ECM) deposits such as collagen fibers that contribute to wound healing.(26,32,33). The main process in the wound healing phase is the transition from the inflammatory to the proliferative phase, when the inflammatory phase is required for hemostasis and recruitment of cytokines that protect against pathogens and help eliminate dead tissue. However, if there is prolonged inflammation will result in deregulated differentiation and activation of keratinocytes, inhibiting wound healing. During the proliferation phase, it is closely related to the inflammatory response to transition to the anti-inflammatory process required in the proliferation and granulation phase of wound healing.(34)

\section{Conclusion}

The combination of A-PRF and HA increases the GI in DFU healing by reducing the inflammation state which will induce the angiogenesis process. Clinically, the application of A-PRF and HA combination showed to reduce pain better than the A-PRF alone in DFU patients.

\section{Acknowledgements}

This study was funded by Medical Science Doctoral Programme, Universitas Indonesia.

\section{Authors Contribution}

RWK , IA, FDS, EY, and SB designed the study, RWK collected the study data. RWK, IA, FDS, EY, and SB did the statistical analysis. RWK, IA, FDS, EY, SI, TS, JR, SB, and MHR interpreted the data. All authors are contributing in preparing the manuscript. MHR gave writing advices and also collected the study fund.

\section{References}

1. Heydari I, Radi V, Razmjou S, Amiri A. Chronic complications of diabetes mellitus in newly diagnosed patients. Int J Diabetes Mellit. 2010; 2: 61-3.

2. Alexiadou K, Doupis J. Management of diabetic foot ulcers. Diabetes Ther. 2012; 3: 4. doi: 10.1007/s13300-012-0004-9.

3. Cho NH, Shaw JE, Karuranga S, Huang Y, da Rocha Fernandes JD, Ohlrogge AW, et al. IDF Diabetes Atlas: Global estimates of diabetes prevalence for 2017 and projections for 2045. Diabetes Res Clin Pract. 2018; 138: 271-81. 
4. Hilton JR, Williams DT, Beuker B, Miller DR, Harding KG. Wound dressings in diabetic foot disease. Clin Infect Dis. 2004; 39(Suppl 2): S100-3.

5. Everett E, Mathioudakis N. Update on management of diabetic foot ulcers: Diabetic foot ulcers. Ann NY Acad Sci. 2018; 1411: 153-65.

6. Naves CCLM. The diabetic foot: a historical overview and gaps in current treatment. Adv Wound Care (New Rochelle). 2016; 5: 191-7.

7. Grazul-Bilska AT, Johnson ML, Bilski JJ, Redmer DA, Reynolds LP, Abdullah A, et al. Wound healing: the role of growth factors. Drugs Today (Barc). 2003; 39: 787-800.

8. Boulton AJM, Armstrong DG, Kirsner RS, Attinger CE, Lavery LA, Lipsky BA, et al. Diagnosis and Management of Diabetic Foot Complications. Arlington: American Diabetes Association; 2018.

9. Schär MO, Diaz-Romero J, Kohl S, Zumstein MA, Nesic D. Plateletrich concentrates differentially release growth factors and induce cell migration in vitro. Clin Orthop Relat Res. 2015; 473: 1635-43.

10. Bielecki T, Dohan Ehrenfest DM. Platelet-rich plasma (PRP) and Platelet-Rich Fibrin (PRF): surgical adjuvants, preparations for in situ regenerative medicine and tools for tissue engineering. Curr Pharm Biotechnol. 2012; 13: 1121-30.

11. Pavan K, Vikram R, Raja B, Jagadish R. Platelet Rich Fibrin: A Second Regeneration Platelet Concentrate and Advances in PRF. Indian J Dent Adv. 2015; 7: 251-4.

12. Vokurka J, Gopfert E, Blahutkova M, Buchalova E, Faldyna M. Concentrations of growth factors in platelet-rich plasma and platelet-rich fibrin in a rabbit model. Veterinarni Medicina. 2016; 61: $567-70$.

13. Sargowo D, Handaya AY, Widodo M, Lyrawati D, Tjokroprawiro A. Aloe gel enhances angiogenesis in healing of diabetic wound. Indones Biomed J. 2011; 3: 204-15.

14. Fathi W. The effect of hyaluronic acid and platelet - rich plasma on soft tissue wound healing: an experimental study on rabbits. AlRafidain Dent J. 2012; 12: 115-25.

15. Sallam A, El-Sharawy A. Role of interleukin-6 (IL-6) and indicators of inflammation in the pathogenesis of diabetic foot ulcers. Aust $\mathrm{J}$ Basic Appl Sci. 2012; 6: 430-5.

16. Snijders GF, van den Ende CHM, van den Bemt BJF, van Riel PLCM, van den Hoogen FHJ, den Broeder AA, et al. Treatment outcomes of a Numeric Rating Scale (NRS)-guided pharmacological pain management strategy in symptomatic knee and hip osteoarthritis in daily clinical practice. Clin Exp Rheumatol. 2012; 30: 164-70.

17. Kartika RW, Alwi I, Suyatna FD, Yunir E, Waspadji S, Suzzanna I, et $a l$. The use of image processing in the evaluation of diabetic foot ulcer granulation after treatment with advanced-platelet rich fibrin + hyaluronic acid. Sys Rev Pharm. 2020; 11: 519-26.

18. Geerlings SE, Hoepelman AIM. Immune dysfunction in patients with diabetes mellitus (DM). FEMS Immunol Medical Microbiol. 1999; 26: $259-65$.
19. Arsianti RW, Parman DH, Lesmana H, Taufiqqurohman M. Effect of electrical stimulation in lower extremity as physical exercise in type 2 diabetes mellitus patients. Indones Biomed J. 2018; 10: 62-5.

20. Sridharan K, Sivaramakrishnan G. Growth factors for diabetic foot ulcers: mixed treatment comparison analysis of randomized clinical trials. Br J Clin Pharmacol. 2018; 84: 434-44.

21. Ghanaati S, Al-Maawi S, Schaffner Y, Sader R, Choukroun J, Nacopoulos C. Application of liquid platelet-rich fibrin for treating hyaluronic acid-related complications: A case report with 2 years of follow-up. Int J Growth Factors Stem Cells Dent. 2018; 1: 74-7.

22. Tuttolomondo A, La Placa S, Di Raimondo D, Bellia C, Caruso A, Lo Sasso B, et al. Adiponectin, resistin and IL-6 plasma levels in subjects with diabetic foot and possible correlations with clinical variables and cardiovascular co-morbidity. Cardiovasc Diabetol. 2010; 9: 50. doi: 10.1186/1475-2840-9-50.

23. Soewondo P, Ferrario A, Tahapary D. Challenges in diabetes management in Indonesia: a literature review. Global Health. 2013; 9: 63. doi: 10.1186/1744-8603-9-63.

24. Agarwal M, Agarwal V. Platelet rich fibrin and its applications in dentistry-a review article. Int J Clin Exp Med. 2015; 8: 7922-9.

25. Mussano F, Genova T, Munaron L, Petrillo S, Erovigni F, Carossa S. Cytokine, chemokine, and growth factor profile of platelet-rich plasma. Platelets. 2016; 27: 467-71.

26. Nasirzade J, Kargarpour Z, Hasannia S, Strauss FJ, Gruber R. Plateletrich fibrin elicits an anti-inflammatory response in macrophages in vitro. J Periodontol. 2020; 91: 244-52.

27. Gill S, Parks W. Metalloproteinases and their inhibitors: Regulators of wound healing. Int J Biochem Cell Biol. 2008; 40: 1334-47.

28. Tangsupati P, Murdiastuti K. The effect of collagen activation on platelet rich plasma for proliferation of periodontal ligament fibroblasts. Indones Biomed J. 2018; 10: 278-83.

29. Corey SJ, Kimmel M, Leonard JN, editors. A Systems Biology Approach to Blood. New York, NY: Springer New York; 2014.

30. Iio K, Furukawa KI, Tsuda E, Yamamoto Y, Maeda S, Naraoka T, et al. Hyaluronic acid induces the release of growth factors from platelet-rich plasma. Asia Pac J Sports Med Arthrosc Rehabil Technol. 2016; 4: 27-32.

31. Afat İM, Akdoğan ET, Gönül O. Effects of leukocyte- and plateletrich fibrin alone and combined with hyaluronic acid on pain, edema, and trismus after surgical extraction of impacted mandibular third molars. J Oral Maxillofac Surg. 2018; 76: 926-32.

32. Park D, Kim Y, Kim H, Kim K, Lee YS, Choe J, et al. Hyaluronic acid promotes angiogenesis by inducing RHAMM-TGF $\beta$ receptor interaction via CD44-PKC $\delta$. Mol Cells. 2012; 33: 563-74.

33. Wu X, Yang L, Zheng Z, Li Z, Shi J, Li Y, et al. Src promotes cutaneous wound healing by regulating MMP-2 through the ERK pathway. Int J Mol Med. 2016; 37: 639-48.

34. Yang P, Pei Q, Yu T, Chang Q, Wang D, Gao M, et al. Compromised wound healing in ischemic type 2 diabetic rats. PLos One. 2016; 11: e0152068. doi: 10.1371/journal.pone.0152068. 